\title{
Improvement of the Practical Ability and Innovative Consciousness of the Engineering College Students with the Robot Teaching Platform
}

\author{
Yi Zhang \\ Suzhou University of Science and Technology \\ Suzhou, China \\ Bangfu Wang \\ Suzhou University of Science and Technology \\ Suzhou, China
}

\author{
Qixin Zhu \\ Suzhou University of Science and Technology \\ Suzhou, China \\ Yongrui Zhao \\ China University of Petroleum \\ China
}

\begin{abstract}
The robot practical teaching aims at training students' innovation consciousness and engineering practice ability. This paper states the effect of robot innovation practice teaching, teaching platform construction and the teaching reform, so as to explore the way to deepen the reform of robot practical teaching system and teaching model. In the robot practical teaching, it is necessary to take learning as the basis, develop students' innovation consciousness and engineering practice ability to obviously improve their comprehensive quality.
\end{abstract}

Keywords-robot teaching; practical ability; innovative consciousness

\section{INTRODUCTION}

It has become the development tendency and target of high education to train students' innovation consciousness and practical ability. Innovation is the first power to lead the development and the practice is the source of innovation. The engineering practice cannot do without innovation ability. Therefore, the higher education should research and develop the practical teaching system to improve students' innovation consciousness and practical ability, helpful for the reform of practical teaching system. It has become the core goal of the present teaching reform about how to train students' innovation consciousness and strengthen their practical ability. This paper takes the robot innovation practice teaching as the platform, the reform of practical teaching system as the guiding thought and the robot competition as the carrier, having improved students' innovation consciousness and practical ability as well as the overall quality and met the requirements of the society for high-quality talents. However, the problems in the robot teaching cannot be ignored:

\section{A. The Teaching Contents Cannot Keep Pace with the Development Speed of Robot}

With the emergence and application of the industry 4.0, a lot of energy and material resources have been input in the research and development as well as manufacture of the robot by many countries. The robot industry develops very fast, while most of our syllabuses don't change in years, lagging far behind the development of robot technology. Meanwhile, teachers give a class in accordance with the syllabus instead of updating the teaching contents. Most courses contain the traditional and basic contents, some of which haven't been used. The progress and the latest achievements about the robot research cannot be imparted to students.

\section{B. The Setting of Teaching Links Is Unreasonable}

The teaching link of robot education is unreasonable. Most universities provide theory courses in the robot education, lacking of practical teaching. Teachers pay too much attention to teaching the theory course instead of the practical training, which is the best method to train students' engineering practice ability and innovation consciousness, and the essential part in training students to analyze and solve practical problems with knowledge.

\section{The Product of Robot Teaching Is Nonstandard}

At present, many manufacturers produce and sell education robots. Most of them are small enterprises without unified standard, incompatible with low system openness. The secondary development cannot be carried out, not so useful to students' learning.

\section{THE IMPORTANT ROLE OF THE ROBOT INNOVATION} PRACTICE TEACHING IN TRAINING STUDENTS' INNOVATION

\section{CONSCIOUSNESS AND PRACTICAL ABILITY}

Robots are machines operating automatically. It can be commanded by human beings, operate the programs sorted in advance as well as run according to the principles made by artificial intelligence technology. It assists or replaces people's work, like the production and construction or dangerous work. [1] The robot is the typical mechatronics product. The electromechanical integration technology integrates the mechanical technique and the electronic technique, having 
gained the unprecedented development and become a system technology covering the computer technology and the information technology, automatic control technology, sensing detection technology and servo drive technology as well as mechanical technique, with the soaring development of the computer technology and its wide application in the mechatronics products. The robot technology is an interdisciplinary and comprehensive new-rising subject. The robot is highly integrated and organic. The robot education refers to the teaching activities with the main teaching contents of assembling and operating the robot or taking robots as the teaching carrier, so as to stimulate students' learning interest and train their comprehensive ability. The effect of robot innovation practice teaching shows in the following three aspects [1-3]:

\section{A. Train Students' Interests in the Engineering Practice Teaching}

In today's engineering practice teaching, most universities have used the "little hammer" as the carrier of engineering practice for many years. Because of the highly similar practical contents and the outdated teaching contents, students are not interested in the engineering practice teaching, resulting in the poor teaching effects. It can be changed by taking the robot as the carrier of practical teaching. At the meantime, because robots operate automatically with wide varieties and different structures, students without experience can design some robots with simple structure and procedures, like the robot with single motor, which only needs one motor to provide the power and depends on the mechanical structure. It will greatly lower the level of difficulty for students to learn robots and the mysterious feelings for it, letting them get interested in robots. With the deeper learning of robots, robots with more complicated and difficult functions can be designed. After the initial learning, students are not satisfied with the current situation, pursuing more intelligent design. It requires them to learn more knowledge and carry out deeper research. It is a process with innovation and practice. Meanwhile, it stimulates students' thirst for knowledge and interests in innovation and practice.

\section{B. Train the Active Innovation Consciousness and the Enthusiasm in Learning the Engineering Practice Activity}

In the robot practical teaching, the teacher assigns the design tasks for students at the early stage of teaching, details the functional requirements for robots and guides students to collect the learning materials. Under the guidance of them, students design the robots independently through the formulation, modification and implementation of the overall plan, changing from the passive learning to the active learning to analyze and solve problems independently. Meanwhile, they can combine the theoretical knowledge with the practice, using theories to guide the practice. In order to train students' innovation consciousness, it is necessary to focus on students instead of teachers, strengthen the teacher's guidance and the communication between teachers and students, and create a good and harmonious teaching atmosphere. Only in this way can we fully train students' initiative in innovation and the enthusiasm in the engineering practice activities. The practical teaching, design and manufacture of robots enable students to imagine, boldly query and discuss as well as experiment repeatedly with the existing knowledge in the relaxed and harmonious atmosphere. In this way, students' tenacious quality will be trained, and their innovation consciousness and the enthusiasm in learning the engineering practice activities will be strengthened.

\section{Train Students' Teamwork Spirit}

In the robot practical teaching and design, because of the limitation of students' knowledge layer and manipulative ability, teachers often divide the students into groups to discuss, compile and debug the program, and then make the robot, summarize problems appeared in the operation. High quality robots will be designed and produced through students' teamwork spirit. Students should compete with, learn from and help each other. An atmosphere of team learning should be created to let students explore and learn pleasantly. Under the big team, there should be two or above groups for each program, so that they can compete and exchange experience frequently to make progress continuously. The solidarity and cooperation within the group is important. The tacit understanding is more important between the groups even the different competition groups. A competent student should be in the team to unite all students. This student must have the power of determined will, don't give up easily, be adept in analyzing the characteristics of the opponents and learn from others' strength, lead students in the group. Meanwhile, he can move and drive others by his behaviors. This is the team spirit.

The group members should divide the work and cooperate, which is the cooperation model required in the future society. Therefore, the robot practical teaching can train students' teamwork spirit.

\section{THE IMPLEMENTATION AND REFORM OF THE ROBOT INNOVATION PRACTICE TEACHING PLATFORM}

A good engineering practice platform must be provided to train students' practical ability and innovation consciousness. Our school has built one in the engineering training center: the robot innovation base. It has open laboratories for students and teachers to carry out innovation activities and scientific researches at different levels and specialties. It consists of three parts:

1. The mechanical design and manufacture platform focusing on the mechanical structure innovation, providing conditions of the engineering practice teaching for mechanical engineering students and enables them to participate in some simple practical activities of robot innovation from junior grades, training their engineering practice ability, the ability in mechanical design and manufacture as well as the innovation consciousness.

2. The electronic design and manufacture platform focusing on electronic innovation design, providing conditions of the engineering practice teaching for students in specialties like electronics, control and mechanical electronics. It bases on the practice of electronic design and manufacture at the junior grade and improves students' practical ability through designing some simple control circuits and systems. Meanwhile, with the deep implementation of practice and the 
improvement of students' ability, students can design and manufacture at higher levels.

3. The robot design platform focusing on the design and manufacture of electromechanical system. It is a comprehensive platform basing on the former two platforms and requiring teamwork. Students must have certain basis after going through the practical learning of one of the two platforms. Design teams can be built according to the function and design requirements of robots, so that they can design and manufacture robots.

The robot innovation base can train undergraduates' practical ability and support the discipline construction, the laboratory construction and teachers' scientific research. When building the robot engineering practice platform, we also reform the practical teaching model:

1. Use the new teaching model of "ability plus innovation practice" and define the thinking of "ability, practice and innovation" to promote students' overall development;

The practical teaching center divides the practical contents into four levels, the engineering cognitive level, the engineering basic training, the engineering comprehensive training and the engineering innovation training, details the teaching contents and seizes the main line to train the innovation consciousness and engineering practice ability, making the target of practical teaching clear and building a complete, organic and distinctive practical teaching model. The three levels emphasize strengthening students' engineering practical ability. The last level is to stimulate their innovation potential. Thereby, the whole practical teaching system will form the teaching model of ability plus innovation practice. The practical teaching model of ability is the basis and the teaching model of innovation practice is the promotion and expansion as well as the essence in the reform of practical education system.

2. Student-oriented teaching system of engineering training should be built with the engineering practice ability and innovation consciousness as the training objectives, discipline competition as the opportunity, paying attention to students' personality development and dividing them by different levels.

The teaching model of innovation practice must find out the feasible carrier: In the practical teaching, the teaching model of innovation practice adapting to the development of our school has been explored through training students' engineering practice ability and innovation consciousness and integrating the physical truth of the engineering practice teaching with the help of the robot competition. At the meantime, the teacher should correctly understand the guiding role of competition. The competition is only a form and means to check and stimulate instead of the ultimate goal of practical teaching; the results and ranks of the competition are important but not the only evaluation standard. The teacher should pay attention to the teaching process before the competition and the improvement of students' ability.

3. Build the practical teaching system integrating uniform requirement with personality development
Transform some practice conditions, update some practical project and contents and realize the self-selection or creation of some projects as well as encourage the "diversified" selfdesigned practical projects and contents. Meanwhile, standardize the open practice classroom and make the proportion of the open practical projects reaches up to $60 \%$. Methods:

- Reserve the unified time arrangement of the practice project, making it flexible for students.

- Arrange the practical teaching contents according to the planned time and allow students to prolong the practice time.

- After choosing or creating the practice project, the student team can appoint the time to do experiment ahead of time. The practice time can be prolonged in the practical teaching. Without permission, not allow delaying.

- The experiment and training related to the scientific research project of students and the competition team can be carried out in the laboratory under the guidance of the teacher.

- Students with strong interests can agree upon the time through consultation with the teacher and conduct other experimental projects in the laboratory.

4. Renovate the "university-enterprise cooperation mode" and build the good environment for engineering practice

Strengthen the university-enterprise cooperation, employ experienced technicians to serve as the instructors of practical teaching and give the professional lectures to students regularly or irregularly as well as impart the latest technology from the forefront of production to the students; on the other hand, introduce and use the enterprise practice base and intensify the laboratory construction. Meanwhile, the technical backbone of enterprises can serve as the instructor to expand and update the contents and requirements of the practical link, letting students feel the "real" engineering practical training and forming a good environment for the engineering practice.

\section{ACHIEVEMENTS OF THE RoBOT INNOVATION PRACTICE PLATFORM}

In recent years, the students of our school have participated in the robot competitions like the China Robot Contest and RoboCup (China Region) open tournament and have won seven national and provincial level trophies of the second place and the third place as well as 82 honor certificates. It shows the teaching reform of our school in the robot innovation engineering practice teaching has achieved good effects.

\section{CONCLUSION}

Nowadays, the innovation consciousness and practical ability are the teaching objectives of universities. The robot innovation practice education has provided a new platform for the innovation consciousness and practice ability education. It is also the innovation of the quality-oriented education. Some new methods of the robot practical teaching have been 
proposed and achieved good teaching effects through researches on the physical truth and reform in the robot teaching of innovation practice of our school.

\section{REFERENCES}

[1] Dong Cuimin. Cultivation of College Students' Innovation Consciousness and Ability with the Platform of the Robot Education [J], Research and Exploration in Laboratory, 2011, 9(30): 223-224: 320

[2] Liu Shujun. Research on the Engineering Practice Mode on the Basis of the Robot Innovation Training [J], Course Education Research, 2012, 10 (the second): 241-242

[3] Li Xia. Fundamentals of Robot Techniques_ Exploration on Course Teaching - on the Basis of Exploration on the Interest-driven Learning Method [J], Agricultural Network Information, 2015, 1: 132-135

[4] Baidu Baike. 